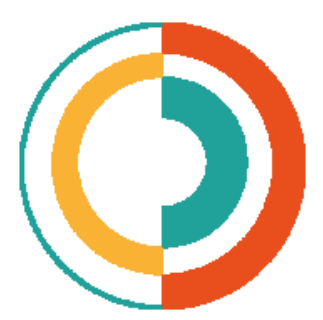

\title{
A documentação de atividades de leitura na EAD com o uso da técnica do rastreamento ocular
}

\section{Documentation of reading activities in distance education with the use of the eye tracking technique}

\author{
Eduardo Santos Junqueira $^{a}$; Elisangela Nogueira Teixeira ${ }^{b}$; Espedito Roza Mesquita ${ }^{c}$ \\ a Universidade Federal do Ceará, Fortaleza, Ceará, Brasil - eduardoj@virtual.ufc.br \\ b Universidade Federal do Ceará, Fortaleza, Ceará, Brasil - elisteixeira@letras.ufc.br \\ c Universidade Federal do Ceará, Fortaleza, Ceará, Brasil - espedito.mesquita@gmail.com
}

Palavras-chave: Rastreamento Ocular. Leitura. Educação a Distância. Fórum Virtual.

Keywords: Eye Tracking. Reading. Distance Education. Virtual Forum.
Resumo: O artigo apresenta os procedimentos e os resultados da utilização da técnica do rastreamento ocular em dois estudos realizados com alunos universitários em laboratório de testes com o objetivo de mapear trajetórias de navegação e práticas de leitura on-line deles, em momentos de estudo. No Estudo 1, a técnica foi utilizada para coletar dados enquanto os alunos realizavam atividades reais, no computador, de disciplinas de um curso de licenciatura em Letras, na modalidade semipresencial. Neste caso, o mapeamento abrangeu a leitura de textos no ambiente virtual de aprendizagem e da internet. O Estudo 2, de caráter experimental, permitiu documentar os processos de navegação e leitura de 30 estudantes de curso de licenciatura em Letras, quando participavam de fóruns virtuais utilizando três interfaces distintas. A coleta, com o registro de cada movimento ocular do participante na tela do computador em intervalos de 30 milésimos de segundo em média, gerou dados acurados detalhados. Isso permitiu visualizar e descrever os movimentos e tempos de fixação e de saltos dos olhos por meio do uso de softwares específicos de tratamento dos dados. Os resultados indicaram que os participantes praticaram modos diversos de leitura nos textos e hipertextos, segundo suas necessidades de conhecimento para as atividades realizadas. Além da prática de leitura linear de textos tradicionais, foram documentadas ações de skimming e de scanning nos hipertextos e páginas acessadas, sem o registro de efeitos negativos indesejados para os objetivos almejados pelos participantes, na maior parte das ações.

Abstract: The article presents the procedures and results of the use of the eye tracking technique in two studies conducted with college students in a test laboratory to map their navigation trajectories and online reading practices during their study activities. In Study 1, the technique was used to collect data while undergraduate students performed real course activities in the computer. In this case, the mapping covered the reading of texts in the learning management system and on the internet. Experimental Study 2 allowed documenting the navigation and reading processes of 30 undergraduate students when participating in virtual forums using three different interfaces. The collection, recording each participant's eye movement on the computer screen at 
intervals of 30 milliseconds on average, generated detailed accurate data. This allowed us to visualize and describe the movements and times of fixation and eye jumping through the use of specific data processing software. The results indicated that the participants practiced different ways of reading the texts and hypertexts according to their knowledge needs for the activities performed. In addition to the practice of linear reading of traditional texts, skimming and scanning actions were documented in the hypertexts and pages accessed, without registering undesirable negative effects to the objectives sought by the participants in most actions.

\section{INTRODUÇÃO}

A leitura dos estudantes, no contexto da educação a distância (EaD), nos hipertextos e interfaces digitais, compreende um movimento relativamente aberto, interativo e pouco previsível através do espaço virtual, articulado previamente pelos designers e possivelmente rearticulado pelo usuário, formado de nós e outros tipos de conexões entre eles, os links. Constitui-se a possibilidade de que cada leitor construa sua própria navegação e leitura pelos textos (que também podem ser não-lineares) e interfaces, delineando sentidos próprios, pois o acesso a essa coleção de itens, estruturas, conteúdos e links pode ocorrer de forma aleatória, instável e imprevisível. Isso enseja novos e pouco conhecidos arranjos de leitura e formas de processamento do texto e integração das informações que, também no contexto da $\mathrm{EaD}$, instauram desafios e perguntas sobre o processo de aprendizagem vivenciado pelos estudantes e ainda pouco conhecido, e que necessita ser melhor compreendido.

Esse artigo relata ações de pesquisas empíricas desenvolvidas em dois estudos subsequentes realizados com estudantes de uma universidade pública: o Estudo 1 abrangeu ações de navegação e leitura de estudantes da modalidade a distância semipresencial, em um ambiente virtual de aprendizagem (AVA) da referida instituição e na internet aberta, e seu objetivo foi mapear trajetórias e modos de navegação e de leitura de estudantes da universidade em seus momentos de estudo on-line. O Estudo 2 investigou a navegação e a leitura de estudantes de um curso presencial de licenciatura em Letras da referida universidade, em interfaces experimentais de fórum virtual que simulavam três contextos distintos de $\mathrm{EaD}$. Seu objetivo principal foi compreender como essas distintas interfaces interferiam de forma positiva e negativa no processo de navegação e de leitura dos estudantes, a fim de se obter parâmetros para a melhoria da aprendizagem on-line. Em ambos se utilizou, para a coleta de dados sobre a leitura em tela, a técnica do rastreamento ocular no registro e na análise das ações dos estudantes no laboratório de testes. Ao longo deste artigo, serão descritas características dessa 
técnica de coleta de dados e seu uso nos dois estudos, bem como serão apresentados alguns resultados obtidos.

\section{LEITURA E APRENDIZAGEM ON-LINE}

As ações do estudante no AVA e na internet podem tomar variadas formas, modos e trajetórias, abrangendo a leitura de conteúdos digitais de diversos modos e linguagens (texto, hipertexto, vídeos, infográficos, imagens etc.). Constitui-se, assim, a leitura cognitiva que visa à decodificação e compreensão culturalmente situada dos textos. Mas a leitura também adquire um aspecto mais mecânico, qual seja, destinar-se a buscas e pesquisas diversas para se localizar uma informação desejada, configurando-se assim como uma leitura procedimental (RIBEIRO, 2012), em que o leitor navega e escaneia os textos, adotando procedimentos ainda pouco conhecidos e compreendidos. Ficam assim caracterizadas leituras do tipo scanning e skimming, ou seja, a cobertura pelo olhar do leitor de uma área extensa, sem profundidade, a fim de localizar algo, e a cobertura de uma área extensa, a fim de mapeá-la de forma rápida e superficial, respectivamente (PADOVANI; MOURA, 2008). Trata-se aqui do leitor navegador que pratica o ato de perscrutar as interfaces digitais e ler os conteúdos apresentados na tela, em ações que se interinfluenciam e tornam complexo o ato de ler.

Essa leitura procedimental, que também pode ser chamada de navegação on-line, pode gerar desorientação espacial (PADOVANI; MOURA, 2008) e ocasionar sobrecarga cognitiva (DESTEFANO; LEFEVRE, 2007), pois demanda esforço adicional do leitor para processar diversas informações e realizar múltiplas tarefas. É possível ocorrer também o fenômeno da digressão embutida (PADOVANI; MOURA, 2008), quando a própria rede incita a exploração de diversas trilhas e opções, levando o leitor a perder o foco, ainda que apenas temporariamente. São ocorrências não desprezíveis, tendo-se em vista que estudantes, particularmente aqueles envolvidos em cursos on-line a distância, buscam frequentemente outros conteúdos associados aos seus estudos, para além daqueles disponibilizados pela instituição de ensino no respectivo AVA (JUNQUEIRA, 2010).

A leitura em tela pode ser estudada por meio de dois processos. O primeiro deles é o que diz respeito aos mais básicos processos mentais implicados no âmbito da compreensão leitora, ou seja, os processos biológicos. No entanto, o segundo processo diz respeito ao fato de que nossos processos biológicos estão permeados por processos culturais. 
Para compreender o percurso de aprendizagem de um estudante é essencial levar em consideração os processos culturais de aquisição do conhecimento. Atualmente, uma abordagem experimental do processamento da linguagem escrita e de imagens pode delimitar o seu foco de interesse na compreensão de uma fase essencial, que é a percepção visual da palavra escrita, para posteriormente analisar o resultado desta fase, que pode ser sumarizado em fases que vão do acesso lexical, passam pela integração das palavras em uma oração, pela integração do sentido entre orações e entre segmentos discursivos, até chegar à compreensão total do enunciado completo.

Ao falar de percepção visual da palavra escrita e percepção de imagens, estamos tratando de processos psicológicos de nível básico, que implicam processamentos do tipo bottom-up. Treiman (2001) define o processo bottom-up na leitura como sendo aquele que recebe o estímulo de fora para dentro, ou seja, como um processo de nível básico que, em primeiro lugar, recebe o estímulo visual para depois transformá-lo em imagens no córtex visual primário. Ainda no córtex visual primário, a informação das imagens procura as áreas de identificação de letras, para posteriormente ser enviada às regiões cerebrais de identificação de palavras, de onde são distribuídas para serem tratadas em áreas especializadas no processamento da linguagem, seja em nível oracional ou discursivo. Um processo bottom-up é, em suma, aquele que ocorre sem que anteriormente sejam demandados conhecimentos de mundo ou linguísticos para o início do tratamento da informação visual em forma de palavras.

O processo top-down, por outro lado, se caracteriza pela demanda por informações superordenadas, da ordem do conhecimento enciclopédico (mundo, linguístico etc.) durante o fluxo de leitura. Nele estão implicados os processos culturais que levam o estudante a aprender. O processo top-down é também chamado de antecipação, ou seja, um movimento que prediz o que será percebido físicamente pelo olho. O processo top-down se refere ao tratamento da informação guiado principalmente pelo conhecimento individual anterior à interação com o estímulo visual.

Processos psicológicos mais complexos, do tipo top-down, sucedem e antecedem a percepção visual, podendo ser posteriores e anteriores à codificação da imagem visual em forma linguística. Na leitura, as antecipações são consideradas parte de um processamento top-down, que ocorre independentemente de haver um processamento bottom-up anterior ou posterior de 
decodificação do estímulo visual. São os processos top-down que fazem com que dada forma linguística se decodifique em sentido contextual e se relacione com as demais informações da memória de trabalho, ativadas em dado evento comunicativo. O tempo total de processamento de um termo lido é entendido como o somatório do tempo dos processos bottom-up e topdown, já que a decisão do leitor de passar para o próximo termo ocorre somente depois de ele ter compreendido o sentido do termo lido e o integrado às informações previamente lidas e presentes em sua memória de curto prazo. Há muitas controvérsias em relação a qual dos dois processos seria preponderante na ação de ler. Colocar-se de um lado ou de outro significa sustentar ou não a preditividade na leitura (RAYNER et al., 1998).

Estudo de Just e Carpenter (1980) também apontou os aspectos subjetivos que influenciam a motivação do leitor. Em função de seus objetivos de leitura e da familiaridade com o tema dos textos, o tempo de leitura e processamento pode variar substancialmente. Segundo os autores, a leitura pode ser construída pela execução coordenada de estágios de processamento. Os estágios descritos no modelo apresentado são: primeiro o leitor codifica a palavra, ou seja, processa visualmente o input, transformando-o em uma forma linguística; depois, passa ao acesso lexical, que é o pareamento entre a forma visual e a linguística; em seguida, o sujeito determina qual é o papel semântico desse item lexical; para, finalmente, integrá-lo à informação da sentença na qual está presente. A compreensão do texto como um todo é atribuída à capacidade do indivíduo de relacionar e integrar todas as sentenças do texto.

Diversos modos e estratégias de leitura de textos digitais e de hipertextos foram estudados e identificados. Gomes (2010) reporta estudos que mapearam ações mais estruturadas de leitura de hipertextos, incluindo ações de leitura direta do começo ao fim, releitura de certas passagens após concluir a leitura e releitura de trechos antes mesmo de concluir a leitura do texto completo. $\mathrm{O}$ autor também descreve a estratégia casual, com cliques do leitor nos links movido pela curiosidade, a leitura em busca de informações desejadas e a leitura em coautoria, que "ocorre em hipertextos abertos que permitem inserção de novos links, como no caso dos wikis e blogs, por exemplo" (GOMES, 2010, p. 104). E, por fim, destaca a ação do leitor de buscar estabelecer uma continuidade de sentidos ao ler, construindo coesão e coerência para atingir seus objetivos de compreensão dos conteúdos acessados e lidos.

\section{A PESQUISA COM O RASTREAMENTO OCULAR}


A técnica de rastreamento ocular foi criada há mais de um século por meio de procedimentos invasivos e perigosos, como os realizados por Javal, em 1889. O uso de feixes de luz para refletir os movimentos da pupila introduziu novos padrões de segurança, mas a limitação de movimentos da cabeça dos participantes e a dos movimentos oculares horizontais resistiu por mais de 70 anos. Somente na década de 1970, laboratórios militares desenvolveram processos automatizados que viabilizaram a documentação e o processamento de sacadas oculares, ou seja, movimentos dos olhos de um ponto a outro, o que permitiu a investigação acurada dos movimentos dos olhos para diversos fins de pesquisa (RAYNER, 1998).

Os olhos realizam dois tipos diferentes de movimento: as sacadas e as fixações. As primeiras são movimentos rápidos em que o olho parte de um ponto de fixação e passa a se fixar no ponto subsequente, sem parar em pontos intermediários. As sacadas são, portanto, pequenos saltos de um ponto a outro, cujo tempo varia entre 20 a 40 milésimos de segundo (ms). As fixações, também conhecidas como campo visual, são os espaços onde a informação pode ser conscientemente processada, sempre quando o olhar aí permanecer por algo em torno de 250 ms. O tempo de permanência das fixações variará em função da tarefa cognitiva, mas está compreendido em média entre 150 a 400 ms (RAYNER, 1998). Esse é o intervalo médio de permanência para levar à consciência a informação visual e integrá-la às demais. Esse tempo permite que o indivíduo chegue a construir sentidos. Segundo os estudos de Rayner (1998), uma fixação inferior a $150 \mathrm{~ms}$ não permite levar à consciência a informação visual, mas permite, nos estudos psicolinguísticos, realizar o que ficou conhecido como priming, que é a impressão inconsciente de um estímulo, geradora de uma resposta no indivíduo.

As sacadas, na definição de Rayner (1998), são movimentos da esquerda para a direita dos indivíduos que leem nas línguas ocidentais. Já em línguas como o hebraico e o árabe, os movimentos são em sentido inverso. Para leitores de línguas ocidentais, os movimentos sacádicos inversos representam apenas algo em torno de 10 a 15\%. A fixação do olhar compreende em torno de $2 \mathrm{~ms}$, o que representa na escrita cerca de duas letras. Foi constatado que o tempo de fixação varia em função da dificuldade do processamento da tarefa, ou seja, que a duração das fixações tem variações consideráveis entre sujeitos e também em cada sujeito, dependendo da complexidade da tarefa realizada.

Hoje os rastreadores oculares têm alta resolução temporal e permitem, por meio da análise de software, o fracionamento dos tempos de rastreamento em vários componentes. Outro 
destaque é o fato de que os participantes podem se comportar com maior naturalidade durante as coletas de dados, sem a necessidade de imobilização da cabeça em muitos casos, um fato importante na aquisição e na interpretação de dados sobre várias tarefas que exigem longos períodos de tempo de máquina. A técnica é, portanto, muito eficaz para a investigação da navegação virtual e leitura em tela, permitindo o registro acurado dos pontos visualizados, na tela do computador, e os tempos despendidos pelo participante ao navegar por páginas digitais e ler conteúdos na tela do computador (HOLMQVIST et al., 2011).

Os estudos sobre os movimentos oculares com o uso da técnica do rastreamento ocular na área da educação têm se voltado particularmente para a investigação de possíveis ganhos de aprendizagem de estudantes com estudos experimentais baseados em simulações de cenários, ferramentas e conteúdos (textuais, imagéticos) através do design de experimentos de perspectiva marcadamente cognitivista. Outros estudos, de certa forma associados à aprendizagem, têm sido desenvolvidos na área do processamento de leitura, tendo consolidado um forte campo de estudo da área da Linguística e que se aproxima do campo da educação ao elucidar elementos centrais dos processos de aprendizagem e da compreensão da língua.

A técnica de rastreamento ocular empregada nos dois estudos aqui apresentados consistiu em monitorar a posição relativa dos olhos durante tarefas que envolviam a visualização de estímulos visuais, sejam eles imagens, objetos ou textos escritos, e a leitura de textos na tela. A forma de rastreamento ocular utilizada foi a do rastreamento por vídeo, baseado na detecção da pupila e da córnea, através da emissão de luz infravermelha posicionada na parte inferior da tela do computador desktop, embutida no equipamento de coleta no laboratório de testes, sem fixação da cabeça dos participantes, permitindo movimentos mais livres e naturais durante as coletas.

O Estudo 1 investigou as trajetórias de leitura dos estudantes em ambientes virtuais de aprendizagem e na internet. Este estudo centrou-se na análise das sequências da navegação e leitura dos estudantes a partir do fórum de discussão e fora do AVA. O equipamento de rastreamento documentou os movimentos oculares do estudante sobre a tela do computador, assim como os saltos, fixações e regressões dos olhos em partes da tela. Foi possível rastrear cada movimento feito pelo estudante, cada olhar, cada clique do mouse, permitindo analisar 
os movimentos de navegação de forma precisa, abarcando a complexidade das ações empreendidas pelos participantes do estudo.

Participaram do estudo nove estudantes de $\mathrm{EaD}$ dos cursos de licenciatura em Matemática e em Letras de um polo da Universidade Aberta do Brasil. A coleta dos dados teve a duração de dois semestres letivos. No laboratório, os estudantes foram convidados a utilizar um computador de mesa comum e a agir como se estivessem em momento de estudo, sendo solicitado apenas que começassem suas ações a partir do fórum de discussão de uma das disciplinas cursadas no AVA, no momento da coleta. Os estudantes permaneciam por no mínimo 10 minutos navegando da forma que lhes fosse mais adequada enquanto o equipamento de rastreamento ocular documentava suas ações na tela. Eram realizados pelo menos quatro turnos de documentação da navegação de 10 minutos cada. Nos dois primeiros turnos, o estudante permanecia sozinho no laboratório, enquanto o equipamento documentava a navegação. Nos outros dois turnos, o pesquisador acompanhava presencialmente as ações de navegação e leitura e tomava notas sobre as ações realizadas. Após terem sido concluídos os quatro turnos, o pesquisador entrevistava o participante, procurando compreender, por meio de depoimentos, as ações realizadas nos quatro turnos. Foi realizada a transcrição de entrevistas gravadas em áudio em que os estudantes explicavam seus movimentos detalhadamente. Os depoimentos foram considerados e analisados, o que agregou sentido à análise das trajetórias oculares documentadas.

O Estudo 2 documentou ações de navegação e leitura em fóruns virtuais. Para este estudo, qualitativo e de caráter experimental, a coleta de dados consistiu na documentação, pela técnica do rastreamento ocular, das ações realizadas por 30 estudantes cursistas de licenciatura em Letras da universidade, em três interfaces de fóruns distintas, e de entrevistas semiestruturadas (Figura 1). Para a montagem do experimento, foram selecionados três tipos de interfaces de fórum virtual para desktop, integrantes de um sistema hipermídia, considerando-se seus formatos distintos e contrastantes e considerando-se qualidades ergonômicas e princípios da avaliação das heurísticas de usabilidade (NIELSEN; MOLICH, 1990). 
Fig. 1 - Participante realiza leitura na tela ao participar de fórum virtual experimental durante coleta de dados em laboratório com equipamento de rastreamento ocular.



FONTE: Arquivos das pesquisas.

Os fóruns das três interfaces continham conteúdos autênticos do campo de estudo de Letras, regularmente abordados nas disciplinas introdutórias do curso. A tarefa do estudante era participar do fórum, ou seja, ler o conteúdo de cada fórum contendo a atividade e textos já postados por um tutor e por outros estudantes, e publicar o seu próprio comentário sobre a temática em debate em cada fórum. Nesse aspecto, considerou-se que a tarefa era de baixa complexidade, pois os conteúdos abordados eram elementares para os participantes, que foram informados que seu conhecimento sobre os conteúdos não seria avaliado no experimento. O foco, portanto, incidiu sobre o processo de navegação e leitura nas interfaces e a mecânica da participação no ambiente. Dessa forma, a tarefa incluía quatro ações principais: navegar pela interface do fórum, ler os conteúdos textuais e imagéticos disponibilizados, escrever e publicar seu próprio comentário. Cada estudante realizou três ciclos de navegação para a coleta de dados em cada uma das três interfaces, lendo e publicando nos fóruns 9 vezes no total. A coleta de dados incluiu também a realização de duas entrevistas semiestruturadas com cada um dos participantes, enquanto assistiam, no monitor, às próprias ações documentadas pelo aparelho de rastreamento. Os dados foram analisados utilizando-se softwares dedicados e compatíveis com os arquivos gerados pelo equipamento de rastreamento ocular (Figura 2) bem como por meio de técnicas de estudos qualitativos de análise de dados (BOGDAN; BIKLEN, 1995). 
Fig. 2 - Arquivo de vídeo com documentação de leitura linear de participante da pesquisa é analisado pelo software Tobii Studio para visualização da movimentação ocular no formato sequencial GazePlot.

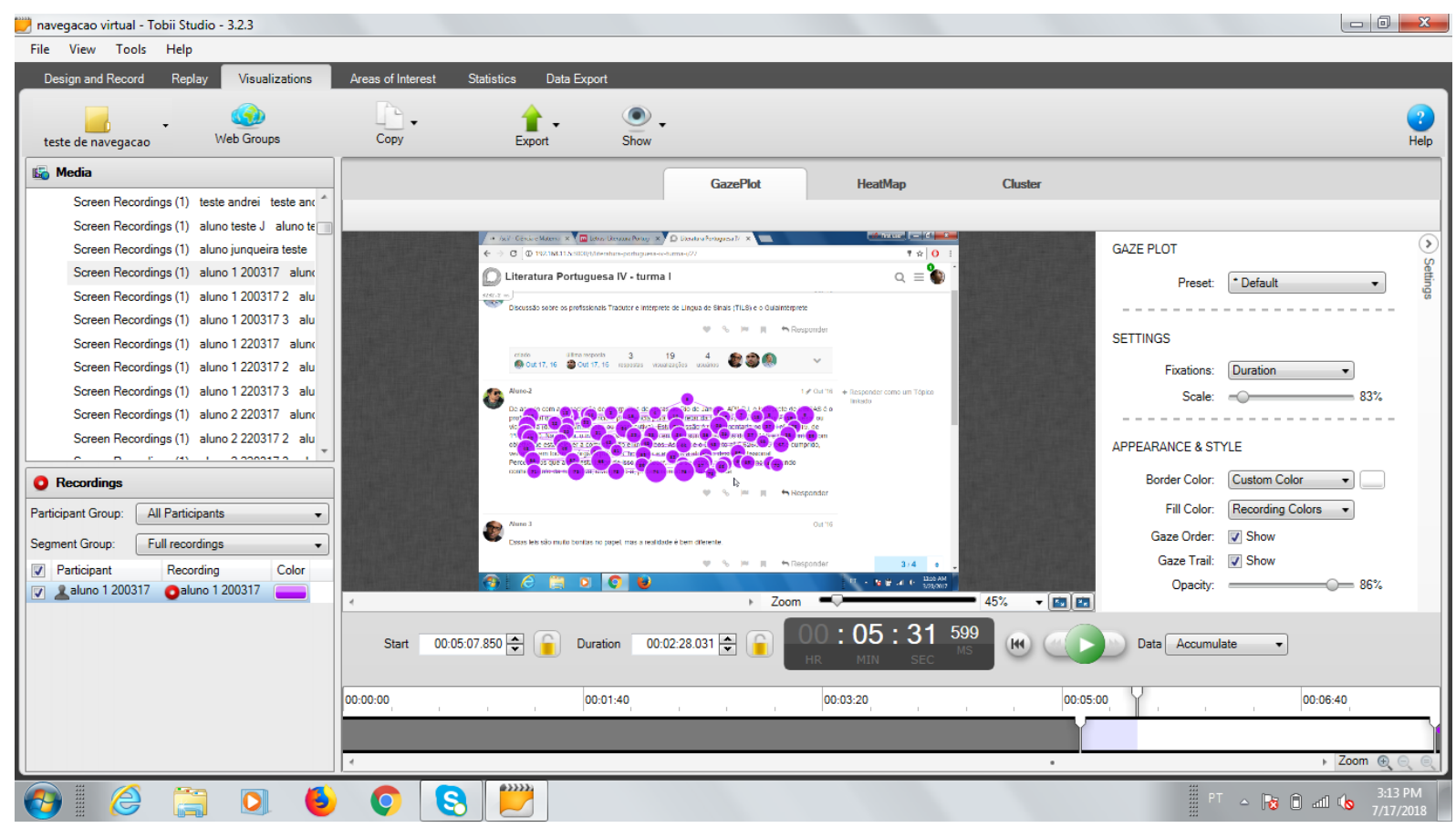

FONTE: Arquivos das pesquisas.

\section{RESULTADOS}

Nos dois estudos, foram documentadas formas diversas de leitura, predominantemente 1) a leitura linear, com fixações dos olhos sobre o texto exibido na tela de modo regular e progressivo, da esquerda para a direita, quando o participante estudava com atenção algum conteúdo a fim de realizar uma tarefa da disciplina ou do fórum digital, e 2) a prática do skimming ou leitura dinâmica, superficial e não linear, com a presença de fixações pouco regulares e a ocorrência de sacadas e saltos dos olhos sobre a tela. Este tipo de leitura estava associado a buscas variadas realizadas pelos estudantes, em particular na internet, no material didático da disciplina disponibilizado no AVA ou nos fóruns, com o objetivo de realizar uma tarefa real da disciplina cursada ou do experimento do Estudo 2.

Ressalta-se que os estudos aqui relatados não buscavam identificar dificuldades de compreensão de leitura dos estudantes, mas algumas ações de releitura, indicadas pela ocorrência de movimentos sacádicos inversos, foram documentadas e atribuídas particularmente devido ao design de uma das interfaces utilizado no experimento do Estudo 2 que, propositadamente, gerava confusão espacial e demandava esforço extra do estudante para realizar a tarefa do fórum. Mas, quando entrevistados, nenhum estudante relatou dificuldades 
na compreensão dos materiais textuais disponibilizados na tela, o que não gerou documentação importante sobre isso.

Para uma melhor visualização das mencionadas ações de leitura documentadas pelo uso da técnica do rastreamento ocular e de softwares específicos para tratamento e análise dos dados foram geradas, além das imagens disponibilizadas a seguir, uma sequência de vídeos curtos que apresentam a movimentação do olhar do estudante sobre a tela do computador ao realizar os dois tipos principais de leitura mencionados ${ }^{1}$.

A seguir serão apresentadas ocorrências frequentes no conjunto dos dados de documentação das leituras realizadas pelos participantes em cada um dos dois estudos. É importante ressaltar que, nos dois estudos, documentou-se a ocorrência da leitura linear tradicional dos textos, mas também foram identificados outros modos de leitura relacionados a características as interfaces digitais em que estavam disponibilizados e aos interesses e necessidades dos estudantes a fim de alcançarem seus objetivos.

No Estudo 1, quando os estudantes identificavam que um material de estudos exibido na tela era de interesse para a tarefa a ser realizada na disciplina cursada, iniciavam uma ação de skimming, ou seja, uma navegação menos detalhada para conhecer o conteúdo (Figura 3). O mesmo tipo de ação ocorreu na leitura de comentários publicados nos fóruns do AVA, onde raramente ocorria uma leitura linear. O scanning também foi realizado muito frequentemente nos fóruns do AVA, para identificar novos comentários disponíveis, intervenções da tutoria etc. Ou seja, o estudante determinava o percurso da navegação e leitura, independentemente da estrutura e do fluxo de ações programadas no AVA, e fórum em particular, buscando encontrar aquilo que lhe era de interesse no momento de estudos. Configurava-se, dessa forma, uma leitura marcadamente autoral, com percursos definidos pelo estudante segundo suas necessidades e interesses. A leitura linear que ocorria, nesses casos, incidia sobre pequenos blocos de texto, como o caso de um comentário em particular publicado no fórum, por exemplo (Figura 4).

\footnotetext{
${ }^{1}$ Ver em: https://drive.google.com/file/d/1i3cujOVxeSew9RELyBnu9DMxoXoLa4b9/view? usp=sharing.
} 
Fig. 3 - Documentação da movimentação ocular indicando skimming de elementos textuais e imagéticos diversos na tela por meio da técnica de visualização em formato de GazePlot, com fixações do olhar a cada 20

ms.

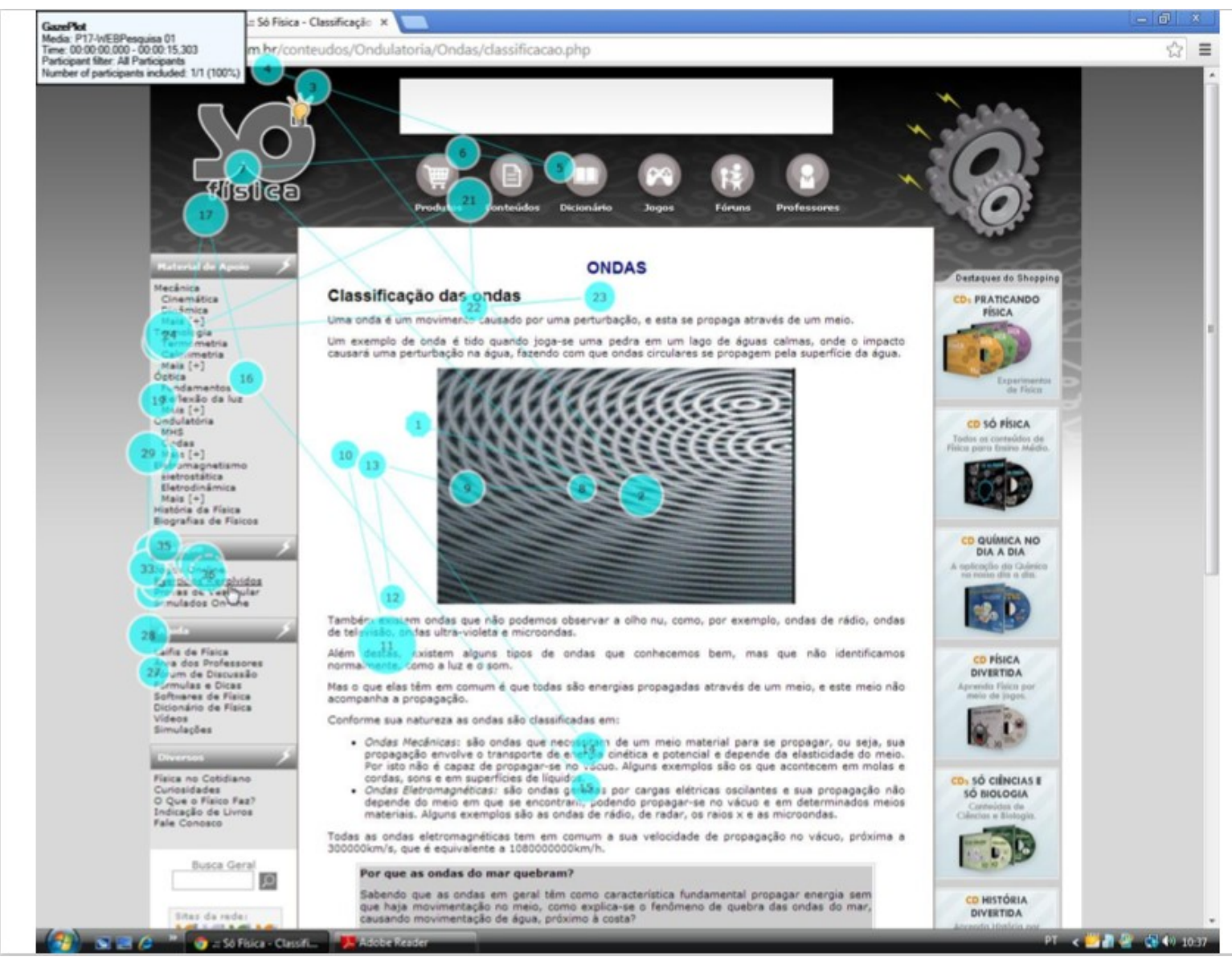

FONTE: Arquivos das pesquisas.

Fig. 4 - O rastreamento ocular permite mapear a sequência numerada da leitura linear de comentários no fórum do AVA através da técnica de visualização em formato de GazePlot, com fixações do olhar a cada $20 \mathrm{~ms}$.

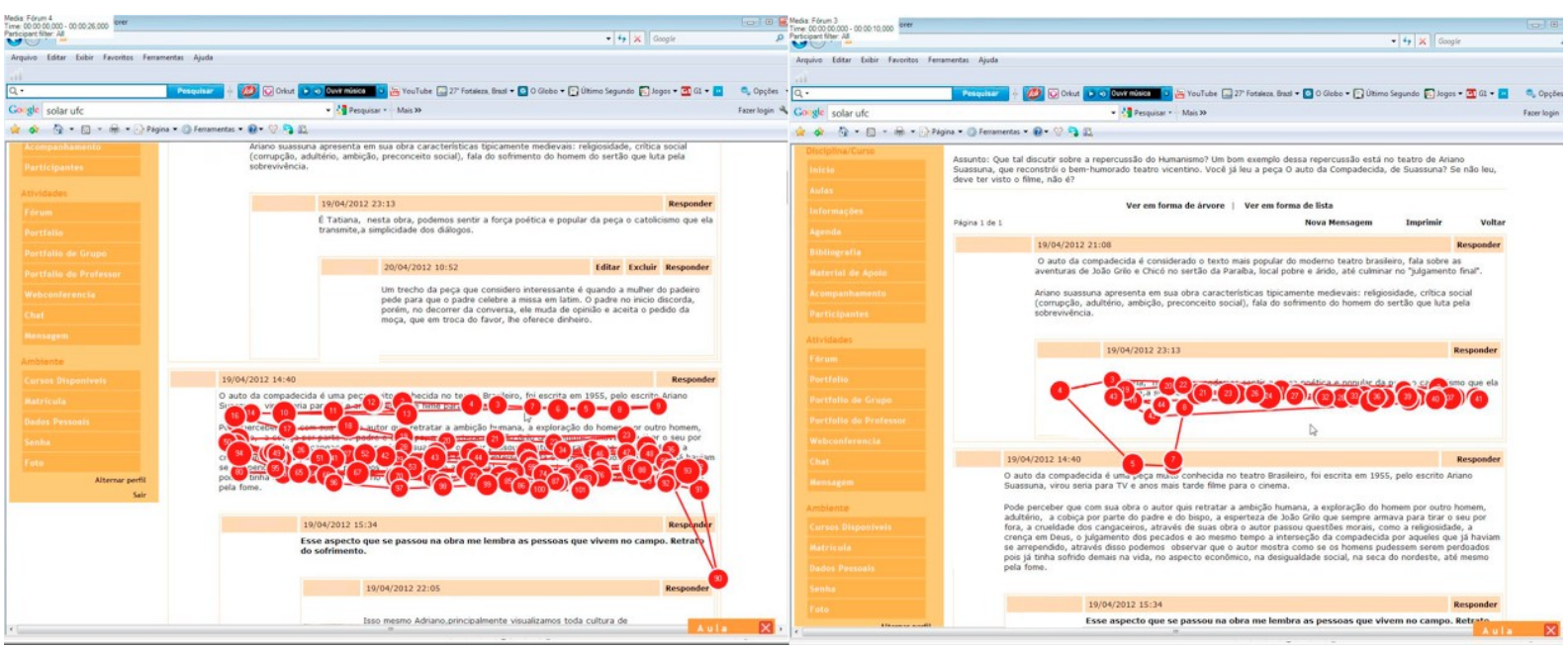

FONTE: Arquivos das pesquisas. 
No Estudo 2 os processos de leitura estiveram contidos nos fóruns experimentais e os participantes, em geral, seguiam uma sequência linear, com fins de compreensão textual, para que pudessem publicar uma resposta aos comentários, dentro da tarefa programada. Essa ação de leitura típica foi documentada inúmeras vezes através do rastreamento ocular (Figura 2). As ocorrências de leitura fora desse padrão também foram documentadas em duas situações, uma positiva e outra indesejada.

No primeiro tipo de ocorrência, observou-se que os olhos dos estudantes saltavam pela tela e fixavam pontos dos textos que já haviam sido lidos anteriormente, e a releitura de alguns trechos ocorria quando buscavam elaborar uma resposta para ser publicada no fórum. Assim, o rastreamento documentou saltos entre diversos pontos dos textos na tela e a leitura em modo skimming identificada foi assim explicada por uma participante:

Pesquisador: Conta para a gente o que você estava fazendo aí [ambos assistem, no monitor, à gravação da tela realizada]?

Estudante 1: Mesma coisa, estou lendo a pergunta, aí eu volto várias vezes na pergunta e depois eu dou uma olhada mais ou menos nas respostas, eu dou uma olhada bem rápida, não me prendo muito o olhar, seria uma leitura dinâmica.

Pesquisador: E, nessa leitura dinâmica, o que você está captando aí?

Estudante 1: Estou vendo o que as pessoas estão falando para eu saber o que eu vou falar também, aí os primeiros [comentários postados no fórum] eu sempre leio um pouco mais, depois eu vou só dando uma olhada um pouco rápida.

(Entrevista Participante X).

Outros movimentos oculares documentados revelavam a ocorrência de perturbações nas leituras registradas e que eram provocadas pelas dificuldades do estudante em compreender o modo de uso da interface digital do fórum a fim de publicar o comentário. Nesses casos, o rastreamento ocular capturou movimentos irregulares (Figura 5) de scanning que não foram causados, no entanto, por dificuldades de compreensão textual. Os estudantes atestaram isso nas entrevistas realizadas após a atividade no laboratório e citaram também a presença de anúncios publicitários, fotografias em tamanho grande e excesso de espaços em branco na tela como elementos problemáticos aos processos de leitura documentados - gerando distrações indesejáveis -, em que os olhos se afastavam dos elementos textuais e realizavam sacadas por outros pontos da tela, tendo sido assim capturados durante o rastreamento. 
Fig. 5 - Ocorreram fixações em vários pontos da tela provocadas pela desorientação do leitor ao tentar compreender como era realizada a publicação de comentários na interface de fórum apresentada.

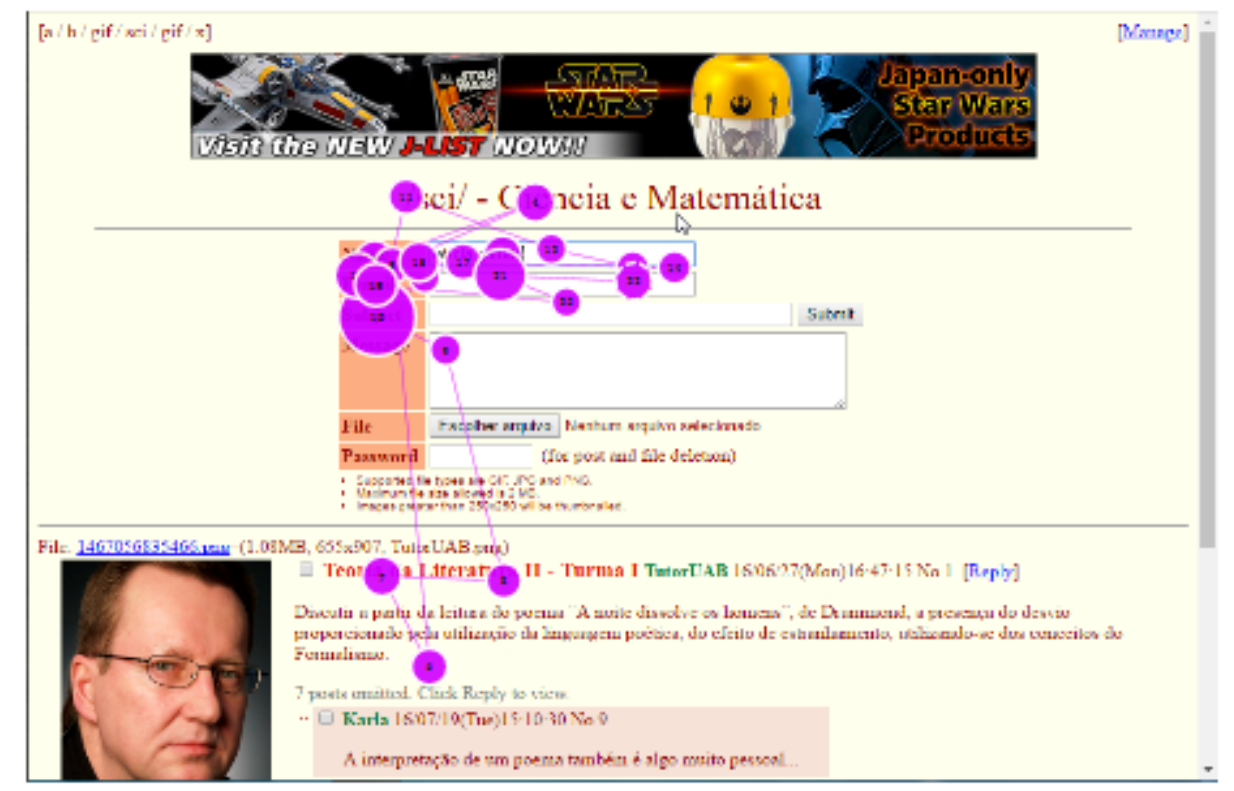

FONTE: Arquivos das pesquisas.

Ao contrário do comportamento ocular documentado dos participantes do Estudo 1, elementos estranhos exibidos na tela perturbaram o processo de leitura dos participantes no Estudo 2, ocorrência documentada por meio do rastreamento ocular e nas entrevistas realizadas. O Estudo 1 foi conduzido com estudantes de $\mathrm{EaD}$ experientes, já habituados ao estudo no computador e que, em entrevistas, afirmaram que anúncios publicitários e links estranhos na tela não geravam distração para eles, fato corroborado pela documentação do rastreamento ocular. Os problemas vivenciados por participantes do Estudo 2, portanto, podem ser atribuídos à diferença de perfil dos dois grupos de participantes, mas também à natureza autêntica do Estudo 1, com materiais e ações de estudo reais da $\mathrm{EaD}$, enquanto a atividade dos fóruns no Estudo 2 era experimental e simulada. Dessa forma, verificou-se que, pelo menos em algumas situações de estudo no computador, elementos adversos disponibilizados na tela podem não ser suficientes para perturbar a leitura e o estudo de alguns estudantes, ainda que não sejam recomendados e nem desejáveis. Estudos mais aprofundados sobre essa ocorrência poderão elucidar melhor os diversos fatores envolvidos, com potenciais benefícios para processos de estudo utilizando-se o computador e ambientes multimídia.

\section{CONCLUSÃO}


Com a ubiquidade tecnológica atual vivida por grande parte da população, a leitura em tela e em rede tornou-se frequente e extrapolou os limites do texto contido na página. Por sua vez, as práticas tradicionais de processar as informações textuais e de conhecer e explorar as possibilidades do hipertexto se expandiram para contextos e telas múltiplos, destacando a exploração de novos espaços multidimensionais pelos aprendizes, inclusive em momentos de aprendizagem formal, como na $\mathrm{EaD}$.

Os dados do mapeamento dos movimentos oculares de estudantes em contextos de $\mathrm{EaD}$ apresentados neste artigo revelaram os percursos de práticas de leitura autoral, quando os participantes extrapolaram as fronteiras do material didático e do AVA e buscaram e leram novos materiais na internet. Nesses casos, além da leitura tradicional do texto, as leituras do tipo skimming e scanning também ficaram caracterizadas, particularmente nos espaços hiperlinkados, pela análise do rastreamento ocular. Essas leituras, segundo os depoimentos dos participantes, contribuíram para enriquecer seus processos de aprendizagem, sendo utilizadas para a realização de atividades programadas das disciplinas cursadas. Ou seja, todos os tipos de leitura documentados impactaram positivamente na aprendizagem dos estudantes, não se tornando evidentes processos cognitivos indesejados e prejudiciais ou dificuldades na integração de informações acessadas, ainda que o estudo não tenha se aprofundado em investigar processamento cognitivo e práticas correlatas dos participantes. $\mathrm{O}$ único elemento negativo evidenciado, conforme demonstrado, foi atribuído a um design claramente desfavorável à leitura (uma interface de fórum virtual com problemas de usabilidade, sendo bastante confusa e poluída), que foi identificado e rechaçado pelos participantes.

$\mathrm{O}$ uso da técnica de rastreamento ocular foi bastante adequado à documentação dessas práticas de leitura na tela do computador, ainda que as coletas tenham sido realizadas no laboratório de testes, fora do ambiente natural de estudos dos participantes. Graças à capacidade do equipamento de coleta de dados, os estudantes puderam utilizar um computador similar a um computador de mesa doméstico e não houve necessidade de fixação da cabeça dos participantes, garantindo-se assim a acurácia do mapeamento das leituras, sem gerar desconforto físico. A coleta de cada movimento ocular sobre a tela do computador em intervalos de tempo de 30 milésimos de segundo em média e programas de tratamento e visualização dos dados, como os recursos de gazeplot e de mapa de calor, permitiram realizar o mapeamento das trilhas percorridas pelos olhos dos participantes na tela durante a leitura com acurácia e sólida evidência empírica. 


\section{REFERÊNCIAS}

DESTEFANO, D; LEFEVRE, J. Cognitive load in hypertext reading: a review. Computers in Human Behavior, v. 23, p. 1616-1641, 2007.

GOMES, L. F. Hipertextos multimodais. Leitura e escrita na era digital. Jundiaí: Paco Editorial, 2010.

HOLMQVIST, K.; NYSTRÖM, M.; ANDERSSON, R.; DEWHURST, R.; JARODZKA, H.; WEIJER, J. Eye tracking: A comprehensive guide to methods and measures. Londres: Oxford University Press, 2011.

JUNQUEIRA, E. Conteúdos hipermodais para fins de aprendizagem: usos em contexto pelos alunos. Educação em Revista, v. 26, p. 371-386, 2010.

JUST, M. A.; CARPENTER, P. A. A theory of reading: From eye fixations to comprehension. Psychological Review, v. 87, n. 4, 1980.

NIELSEN, J.; MOLICH, R. Heuristic evaluation of user interfaces. Proceedings ACM CHI'90 Conference, p. 249-256, 1990.

PADOVANI, S.; MOURA, D. Navegação em hipermídia. Uma abordagem centrada no usuário. Rio de Janeiro: Ciência Moderna, 2008.

RAYNER, K. Eye movements in reading and information processing: 20 years of research. Psychological Bulletin, v. 124, n. 3, p. 372-422, 1998.

RAYNER, K.; REICHLE, E.; POLLATSEK, A. Eye movement control in reading. An overview and model. In: UNDERWOOD. G. (ed.). Eye guidance in reading and scene perception. Londres: Elsevier, 1998.

RIBEIRO, A. E. Convergências e divergências em navegação e leitura. In: COSCARELLI, C. V. (org.). Hipertexto na teoria e na prática. Belo Horizonte: Autêntica, 2012.

TREIMAN, R. Reading. In ARONOFF, M.; REES-MILLER, J. (eds.). Blackwell handbook of linguistics. Oxford, England: Blackwell. 2001. 
Educação Brasileira da Universidade Federal do Ceará. Tem experiência nas áreas de Educação e Comunicação Social, com ênfase em cibercultura, educação on-line/EaD, novos letramentos (new literacies, multiliteracies), pesquisa etnográfica. Possui diversas publicações no exterior e no Brasil. É líder do grupo de pesquisa Linguagens e Educação em Rede (LER).

Elisangela Nogueira Teixeira (elisteixeira@letras.ufc.br) é professora adjunta do Departamento de Letras Vernáculas da Universidade Federal do Ceará. Possui graduação em Letras (Habilitação em Português e Francês) pela Universidade Federal do Ceará (2000), mestrado em Letras pela Pontifícia Universidade Católica do Rio de Janeiro (2003) e doutorado em Lingüística pela Universidade Federal do Ceará (2013). Tem experiência na área de Lingüística, com ênfase em Psicolingüística, atuando principalmente nos seguintes temas: processamento da linguagem, resolução anafórica, movimentação ocular.

Espedito Roza Mesquita (espedito.mesquita@gmail.com) é Graduando do curso de Sistemas e Mídias Digitais da Universidade Federal do Ceará (UFC).

Como citar este artigo de acordo com as normas da revista?

JUNQUEIRA, Eduardo Santos; TEIXEIRA, Elisangela Nogueira; MESQUITA, Espedito Roza. A documentação de atividades de leitura na EAD com o uso da técnica do rastreamento ocular. Texto Digital, Florianópolis, v. 15, n. 2, p. 57-73, 2019.

\section{Contribuição de autoria}

Eduardo Santos Junqueira: concepção e elaboração do manuscrito; coleta de dados; análise de dados; discussão dos resultados; revisão e aprovação.

Elisangela Nogueira Teixeira (especialista em rastreamento ocular e leitura): design do estudo; coleta de dados. Espedito Roza Mesquita (bolsista de Iniciação Científica): coleta de dados; análise de dados.

\section{Financiamento}

Não se aplica.

\section{Consentimento de uso de imagem}

Fig. 1 - Participante realiza leitura na tela ao participar de fórum virtual experimental durante coleta de dados em laboratório com equipamento de rastreamento ocular. FONTE: Arquivos das pesquisas.

Fig. 2 - Arquivo de vídeo com documentação de leitura linear de participante da pesquisa é analisado pelo software Tobii Studio para visualização da movimentação ocular no formato sequencial GazePlot. FONTE: Arquivos das pesquisas.

Fig. 3 - Documentação da movimentação ocular indicando skimming de elementos textuais e imagéticos diversos na tela por meio da técnica de visualização em formato de GazePlot, com fixações do olhar a cada 20 ms. FONTE: Arquivos das pesquisas.

Fig. 4 - O rastreamento ocular permite mapear a sequência numerada da leitura linear de comentários no fórum do AVA através da técnica de visualização em formato de GazePlot, com fixações do olhar a cada 20 ms. FONTE: Arquivos das pesquisas.

Fig. 5 - Ocorreram fixações em vários pontos da tela provocadas pela desorientação do leitor ao tentar compreender como era realizada a publicação de comentários na interface de fórum apresentada. FONTE: Arquivos das pesquisas.

\section{Aprovação de comitê de ética em pesquisa}

Não se aplica.

\section{Licença de uso}

Este artigo está licenciado sob a Licença Creative Commons CC-BY. Com essa licença você pode compartilhar, adaptar, criar para qualquer fim, desde que atribua a autoria da obra.

\section{Histórico}

Recebido em: 28/11/2019

Aprovado em: 03/12/2019 